\title{
Improvement of the Tribological Characteristic of Bimetallic Journal Bearing With Surface Coating by Cold Spray Process
}

\author{
Coşkun Yolcu ${ }^{1, *}$, Gökçe Mehmet Gençer ${ }^{2}$, Fatih Kahraman ${ }^{3}$ and Ayça \\ Demirer Kahraman ${ }^{4}$ \\ 1,2,3 Mechanical Engineering Department, Dokuz Eylül University, İzmir, Turkey \\ ${ }^{4}$ Mechanical Engineering Department, Manisa Celal Bayar University, Manisa, \\ Turkey \\ *Corresponding author
}

\begin{abstract}
Surface properties are important for materials that are in contact with each other. Especially when the lubrication conditions are inadequate, the properties of the materials are the main feature that determines the wear behaviour. Bimetal journal bearing materials are machine materials that are subjected to load and motion. For this reason, attempts are made to improve the wear behaviours of these materials and they are frequently investigated in the literature. In the present study, in order to improve the tribological characteristic of the steel backed copper based bimetallic material SAE 49 was coated with tin, lead and $\mathrm{Al}_{2} \mathrm{O}_{3}$ powders using cold spray process and the microstructure, hardness and wear properties of the samples were investigated. It was observed that the $\mathrm{Al}_{2} \mathrm{O}_{3}$ particles were homogeneously dispersed by the cold spray process. Increasing amount of the soft phases such as tin and lead caused decreasing in hardness. However, these soft phases that had solid lubricant properties in the structure and the hard phase such as $\mathrm{Al}_{2} \mathrm{O}_{3}$ improved the wear behaviour of the sample.
\end{abstract}

Keywords: Cold spray, wear, bimetal, $\mathrm{Al}_{2} \mathrm{O}_{3}$, $\mathrm{SAE} 49$

\section{Introduction}

The engine bearings are produced layered to provide mechanical properties such as desired fatigue strength and wear resistance in the construction where they are used. According to this layer number, the motor engine bearings can be divided into mono metal, bimetal and trimetal groups. Bimetal bearings have a steel backing layer, which provides rigidity to the bearing structure in high temperature and cyclic loads. The second layer is relatively thicker than the backing layer and provides lubrication with elements having solid lubrication properties [Kopeliovich, 2018; Kopeliovich, n.d.). In copper-based bimetallic materials, copper-based layer reduces the friction and wear of the bearing surface. These features, along with their low cost, low weight and high performance, enable these materials to be used in many areas. One of these areas is the automotive industry and these materials are used as internal combustion engine bearings in this area [Amanov et al., 2014, A; Amanov et al., 2014, B].

Surfaces of bearings are exposed to friction during operating. Under ideal operating conditions, fluid film lubrication forms on the contact surfaces of tribo-pair. However, start and stop phases or changes in load can be considered as extreme conditions. Because in these conditions, the lubricant film is generally destroyed and occurs dry friction between tribo-pair. For this reason, mechanical properties of the 
layer that coated on the bearing surface has a great importance (Ji \& Chen, 2016). For this reason, the surfaces of bimetallic materials are usually coated with a third layer called babbitt alloy.

Babbitt alloy consists of soft and hard phases. In this phase, the soft one acts as a solid lubricant and decrease friction, while the harder phase carrying the load during operation. These structures are divided into two groups: lead and tin based. While these structures serve as solid lubricants, intermetallic phases such as $\mathrm{SbSn}$ and $\mathrm{Cu}_{6} \mathrm{Sn}_{5}$ in the structure [Lepper et al., 1997; Zeren et al., 2007].

In order to improve the wear behavior bimetal bearing in this study, cold spray technique was used for coating the surface of SAE 49 bearing material with $\mathrm{Al}_{2} \mathrm{O}_{3}$ included tin and lead alloy and sliding wear performance of samples was examined under dry conditions.

\section{Experimental Studies}

Copper based surface of SAE 49 bimetallic material was coated with DYMET TP63-25 commercial powder by cold spray technique. Chemical composition of SAE 49 and DYMET TP 63-25 were given in Table 1. Cold spray coating was performed with a stand of distance is $10 \mathrm{~mm}$. High compressed air was used as the accelerating gas at a pressure of $2.8 \mathrm{MPa}$ and feeding rate of $8 \mathrm{~g} / \mathrm{min}$.

Table 1: Chemical compositions of bimetal and the cold spray powder (\% wt)

\begin{tabular}{|l|l|l|l|l|}
\hline & \% Tin & \% Lead & \% Copper & \% $\mathbf{A l}_{2} \mathbf{O}_{3}$ \\
\hline SAE 49 & 0,94 & 24,42 & Balance & - \\
\hline TP-63-25 & $35-28$ & $20-17$ & - & $45-55$ \\
\hline
\end{tabular}

Microstructure examinations were performed by Nikon Epiphot 200 optical microscope and Jeol 6060 scanning electron microscope. Thermo Scientific ARL KAlpha X-ray diffractometer (XRD) was also used for analyzing of phases in the microstructures. These analyses were performed with $\mathrm{CuK} \alpha$ radiation and $0.1^{\circ} 2 \theta /$ scanning speed.

Microhardness tests were performed with $10 \mathrm{~g}$ load and $10 \mathrm{~s}$ time duration by Emco-Test DuraScan microhardness tester. Wear tests mechanism was shown in Fig 1. Tests were performed with a diameter wheel of $110 \mathrm{~mm}$, a load of $5 \mathrm{~N}$ and a velocity of $1 \mathrm{~m} / \mathrm{s}$ sliding speed. Every $1000 \mathrm{~m}$ out of $3000 \mathrm{~m}$, the weight loss values were noted and measured. Weight loss was measured with weighing machine with a precision of $0.0001 \mathrm{~g}$.

Figure 1: Wear test mechanism

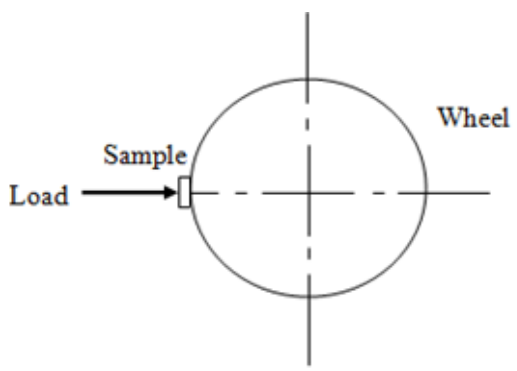




\section{Result and discussion}

Fig 2. shows the surface and cross sectional view of the coating. It can be seen that $\mathrm{Al}_{2} \mathrm{O}_{3}$ the darker grey particles in the figure dispersed in the structure uniformly and the thickness of cold spray coating is about $200 \mu \mathrm{m}$. In addition, no pore formation was observed in the optic microscope examinations. However, in SEM examinations, pores were seen in very small sizes among some $\mathrm{Al}_{2} \mathrm{O}_{3}$ particles. Since the amount of pores formed in the structure were few and the small sized, the effects on the mechanical properties are negligibly. When the coating substrate interface analyzed, absence of any discontinuity defect at the interface can be explained by the successful adhesion of the particles to the surface.

Figure 2: Surface and cross sectional view of the coating
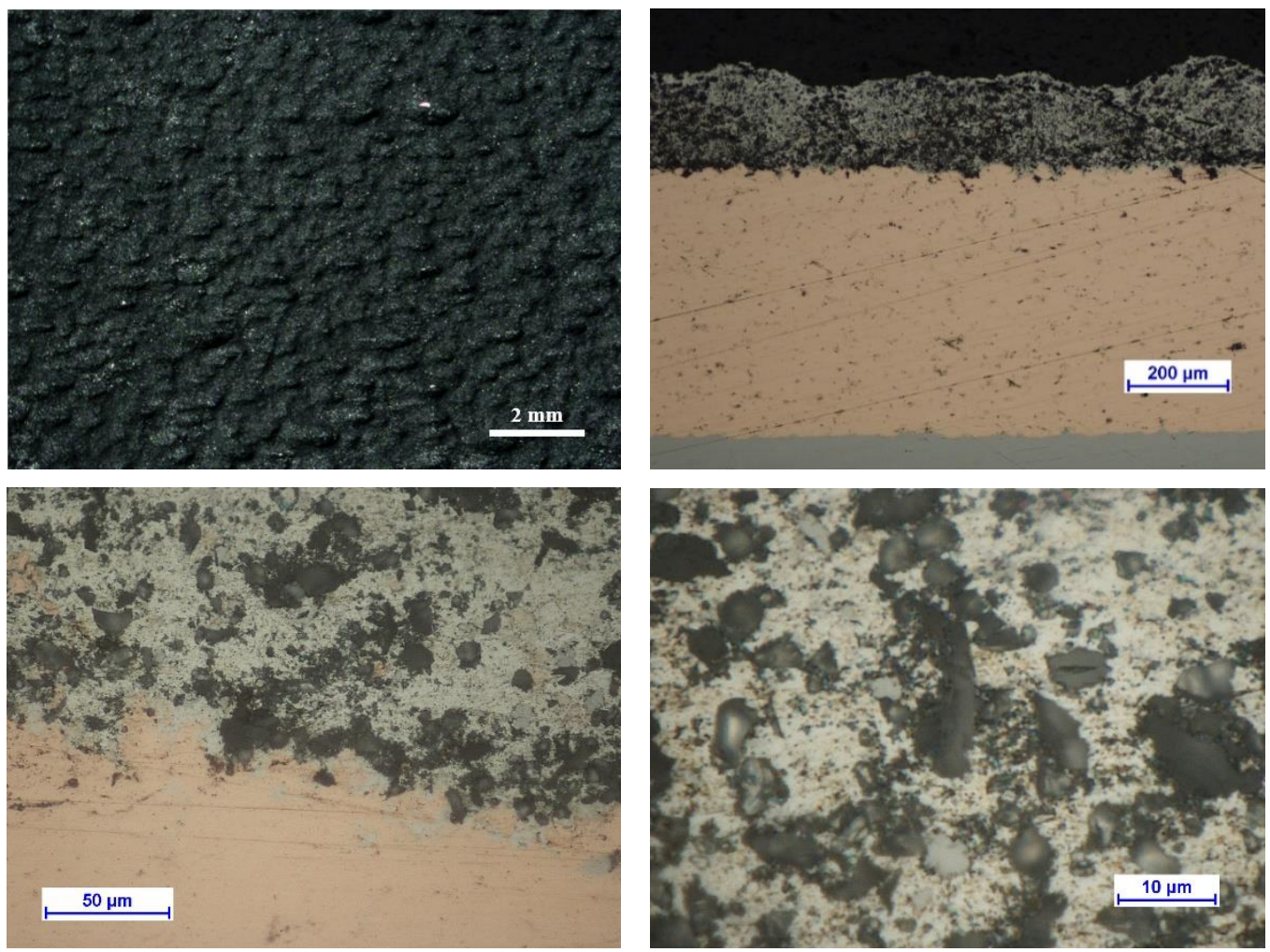

The XRD pattern of $\mathrm{Pb}-\mathrm{Sn}$ and $\mathrm{Al}_{2} \mathrm{O}_{3}$ alloy is shown in Fig 3. It can be observed that the diffraction peaks were mostly $\mathrm{Pb}$ and $\mathrm{Sn}$. In order to determine the phases of the alloy, the sample was examined by EDS, and the results were shown in Fig 4. It can be seen that $\mathrm{Pb}$ and $\mathrm{Sn}$ were uniformly distributed and no macro-segregation was observed in this sample. The point 1,2 and 3 in the figure were $\mathrm{Al}_{2} \mathrm{O}_{3}, \mathrm{Sn}$ and $\mathrm{Pb}$ respectively. 
Figure 3: XRD spectrum of the coating

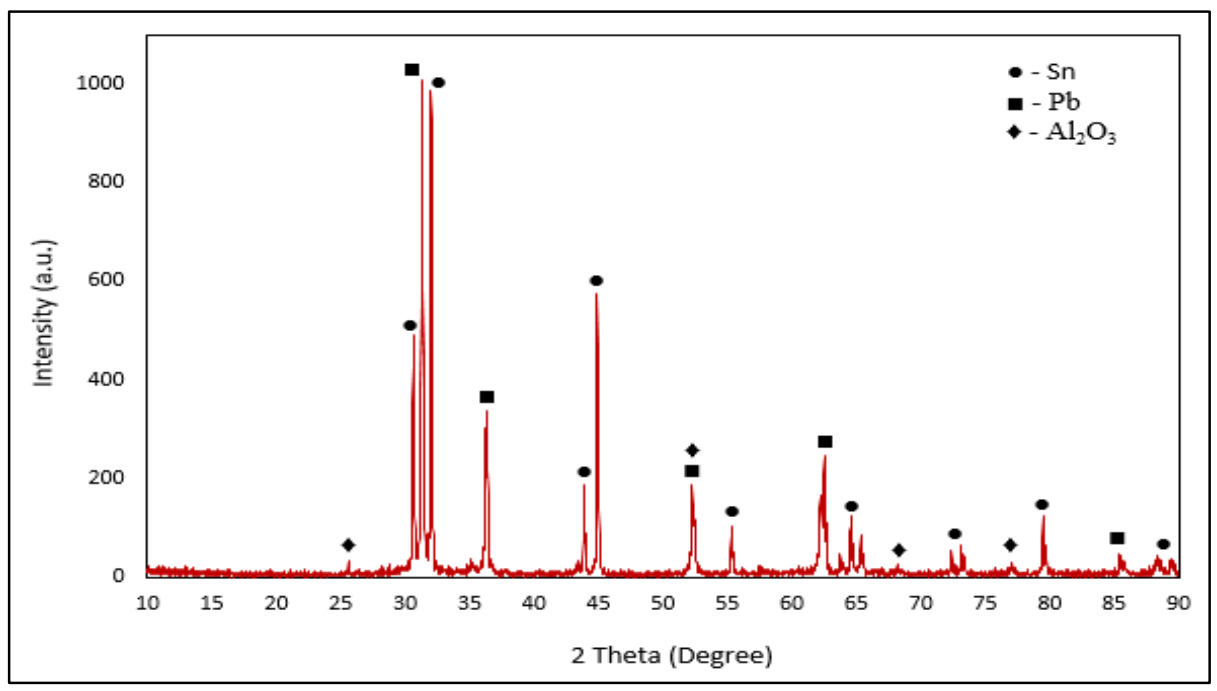

Figure 4: Scanning electron microscopy image of the coating and phases
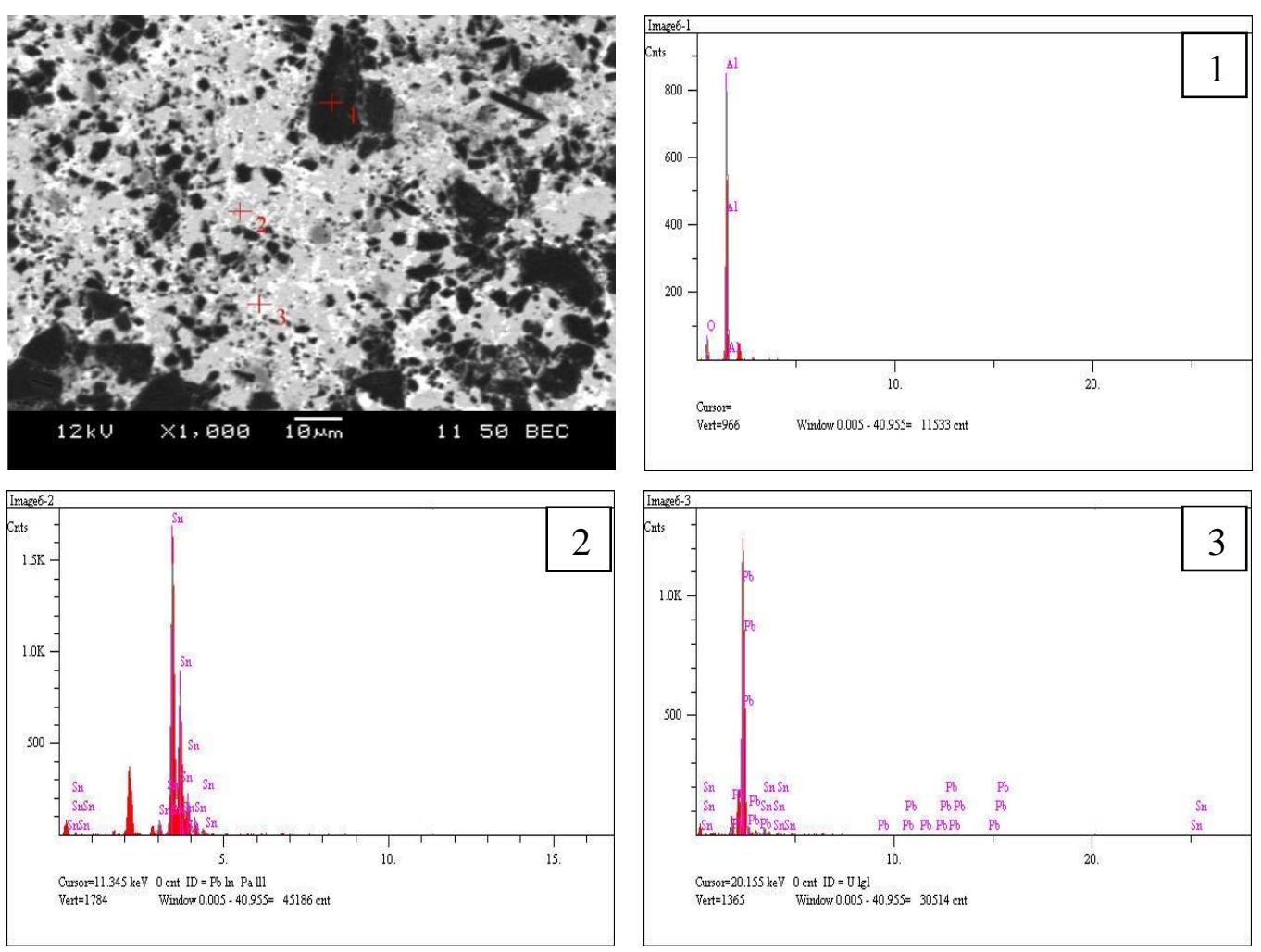

Fig 5. shows the hardness values of the samples. Cold spray coating has $14 \mathrm{HV}$ and copper based layer of SAE 49 sample has $68 \mathrm{HV}$ hardness. It can be said that increase in the amount of tin and absence of copper in the structure caused that the coating has less hardness value in comparison with SAE 49 bearing layer. It is considered that the hardness value of the materials are the main factor determining the wear resistance and the wear resistance is increased by increasing the hardness. However, it should be noted that the main thing that determines wear resistance is the hardness of the contacting asperities of the material, not the bulk material. For this reason, the addition of the second phase particles which are hard in the structure is a 
method which improves the wear resistance of the material (Kathiresan \& Sornakumar, 2010). When wear rates of samples are examined it can be understood that soft tin and lead phases, acting as solid lubricants during the wear test, addition of hard $\mathrm{Al}_{2} \mathrm{O}_{3}$ particles into the structure decreased the weight loss. The weight losses of samples are $31.7 \mathrm{mg}$ and $152.8 \mathrm{mg}$ for coated sample and SAE 49 respectively.

Figure 5: Hardness values and weight losses of samples
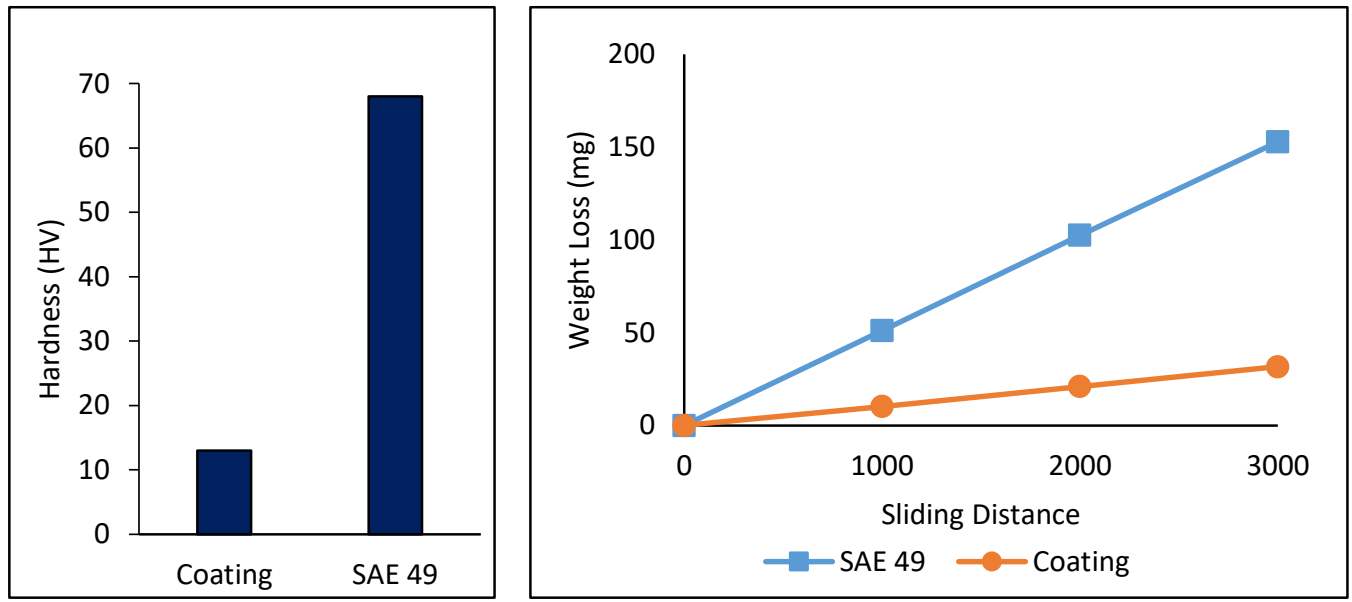

Optical micrograph of wear tracks occurring after the wear tests are given in Fig. 6. Continuous grooves on the wear surface of SAE 49 samples show that the main wear mechanism was abrasion. Abrasion tracks were formed by relatively hard particles that break from the structure during the abrasion test.

Cold sprayed coating make the lubrication task better than the SAE 49 sample due to the very low hardness. This condition is also seen on wear tracks. Wear surfaces of the coating have a polished appearance. In some regions, delamination and abrasive wear tracks are seen in very small areas. The polished surface formed due to the very hard small sized $\mathrm{Al}_{2} \mathrm{O}_{3}$ in the structure. Similarly, in the lining layer, the aluminumbased bearing material is $2-4 \%$ of the silicon is added in the form of fine particles for strengthening the alloy and abrasive polishing the surface of the journal [2].

Figure 6: Wear tracks of samples (a): SAE 49 (b): Coating
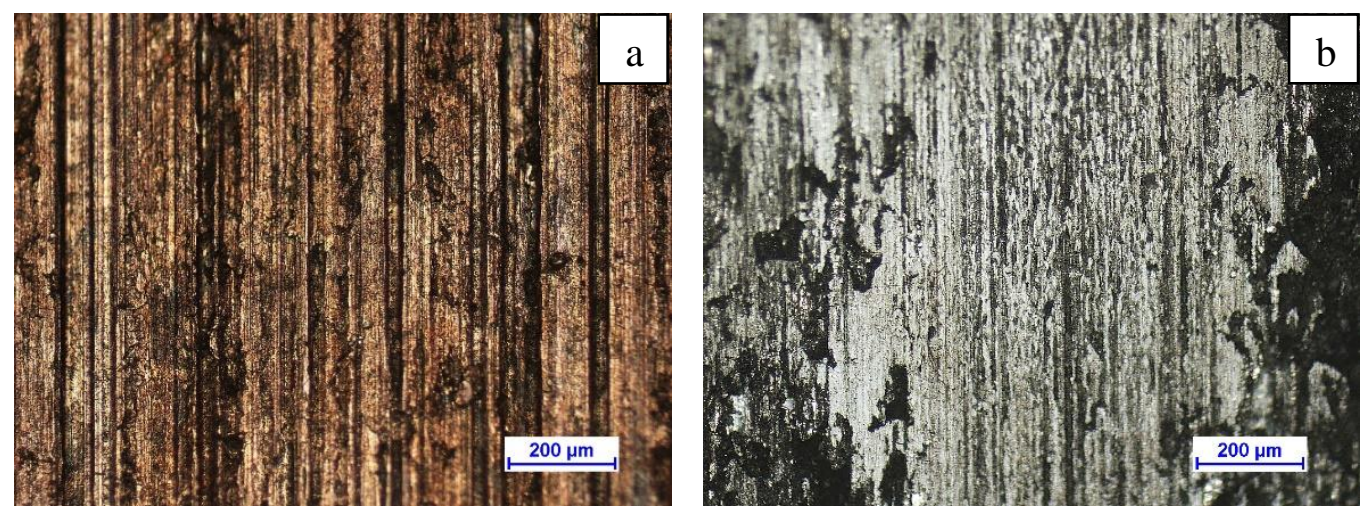


\section{Conclusion}

SAE 49 steel backed copper-based bimetal sample was coated with tin, lead and $\mathrm{Al}_{2} \mathrm{O}_{3}$ alloy by cold spray technique. After the coating, microstructure, hardness and wear behaviour of samples were examined and the results obtaining are as follows:

- It was observed that the $\mathrm{Al}_{2} \mathrm{O}_{3}$ particles were dispersed uniformly in the structure by the coating method.

- Increase in the amount of soft phases in the structure led to decrease in hardness. The hardness of the coating and SAE 49 sample were measured $13 \mathrm{HV}$ and $68 \mathrm{HV}$, respectively.

- Soft phases in the coating caused the formation of adhesive wear regions beside abrasive wear.

- Increase in the amount soft phases and addition of $\mathrm{Al}_{2} \mathrm{O}_{3}$ in the structure led to decrease in wear. The weight loss values were $31.7 \mathrm{mg}$ and $152.8 \mathrm{mg}$ for coated sample and SAE 49 respectively.

\section{References}

[1] Kopeliovich, D. (February 2018). Engine bearing materials. Available: http://www.substech.com/dokuwiki/doku.php?id=engine_bearing_materials

[2] Kopeliovich, D. (n.d) Engine bearing materials. Available: http://kingbearings.com/files/Engine_Bearing_Materials.pdf

[3] Amanov, A., Pyun, Y. S., and Sasaki, S. (2014). "Effects of ultrasonic nanocrystalline surface modification (UNSM) technique on the tribological behavior of sintered Cu-based alloy", Tribology International, vol. 72, pp. 187197.

[4] Amanov, A., Cho, I. S., and Sasaki, S. (2014). "The influence of DLC coating on the mechanical and frictional properties of unpeened and peened $\mathrm{Cu}$-based bimetal under dry sliding conditions", Materials Chemistry and Physics, vol. 143 iss. 2, pp. 814-824.

[5] Ji, X., and Chen, Y. (2016). "Tribological behavior of babbitt alloy rubbing against $\mathrm{Si}_{3} \mathrm{~N}_{4}$ and steel under dry friction condition", Journal of Materials Engineering and Performance, vol. 25, iss. 3, pp. 750-755.

[6] Lepper, K., James, M., Chashechkina, J., and Rigney, D. A. (1997). "Sliding behavior of selected aluminum alloys", Wear, vol. 203, pp. 46-56.

[7] Zeren, A., Feyzullahoglu, E., and Zeren, M. (2007). "A study on tribological behaviour of tin-based bearing material in dry sliding", Materials \& Design, vol. 28 , iss. 1, pp. 318-323.

[8] Kathiresan, M., and Sornakumar, T. (2010). "Friction and wear studies of die cast aluminum alloy-aluminum oxide-reinforced composites", Industrial Lubrication and Tribology, vol. 62, iss. 6, pp. 361-371. 